\title{
西双版纳热带次生林净初级生产量的初步研究
}

\author{
唐建维 $^{1} \quad$ 张建侯 $^{1}$ 宋启示 $^{1}$ 冯志立 $^{1}$ 党承林 $^{2}$ \\ 吴兆录 ${ }^{2}$ 朱胜忠 $^{3}$ 段文勇 $^{3}$
}

(1 中国科学院西双版纳热带植物园热带雨林生态系统定位研究站, 云南预腊 666303)

(2 云南大学生态学与地植物学研究所, 昆明 650091)

（3 西双版纳国家级自然保护区管理局预腊保护所,云南预腊 666300)

摘 要 采用径级标准木和维量分析方法研究了西双版纳热带次生林 4 块不同年龄林分的净初级生产量, 结果表 明: 林分净初级生产量随林龄而增长, 5 年生林分为 $1154.3 \mathrm{~g} \cdot \mathrm{m}^{-2} \cdot \mathrm{a}^{-1}$, 其分配为: 净生长量占 $93.82 \%$, 花果量占 $1.20 \%$, 叶被采食量 $4.97 \% ; 10$ 年生林分为 $1348.5 \mathrm{~g} \cdot \mathrm{m}^{-2} \cdot \mathrm{a}^{-1}$, 净生长量占 $92.83 \%$, 花果量占 $3.25 \%$, 叶被采食量 $3.92 \% ; 14$ 年生林分为 $2212.1 \mathrm{~g} \cdot \mathrm{m}^{-2} \cdot \mathrm{a}^{-1}$, 净生长量占 $91.72 \%$, 花果占 $3.05 \%$, 叶被采食量 $5.23 \% ; 22$ 年生林分为 $2660.1 \mathrm{~g} \cdot \mathrm{m}^{-2} \cdot \mathrm{a}^{-1}$, 净生长量占 $92.09 \%$, 花果占 $3.95 \%$, 叶被采食量 $3.96 \%$ 。林分净初级生产量的器官分配以茎 所占的比例最大, 占 $1 / 3$ 以上; 其次为根, 占 $1 / 5$ 左右; 枝和叶为 $1 / 5 \sim 1 / 7$; 花果所占的比例除 5 年生林分相当少外, 其余 3 个林分约占 $1 / 33$ 。林分净初级生产量的层次分配以乔木层所占的比例最大, 占 $2 / 3$ 以上, 其次为灌木层; 草 本层和层间植物所占的比例相当少。林分的叶面积指数随林龄而增大, 并分别建立了各林分主要优势种及乔木层 样木器官生长量的优化回归模型。

关键词 净初级生产量 热带次生林 西双版纳

\section{A PRELIMINARY STUDY ON THE NET PRIMARY PRODUCTION OF THE SECONDARY TROPICAL FOREST IN XISHUANGBANNA}

\author{
TANG Jian-Wei ${ }^{1}$ ZHANG Jian-Hou ${ }^{1}$ SONG Qi-Shi ${ }^{1} \quad$ FENG Zhi-Li ${ }^{1} \quad$ DANG Cheng-Lin ${ }^{2}$ \\ WU Zhao-Lu ${ }^{2}$ ZHU Sheng-Zhong ${ }^{3}$ and DUAN Wen-Yong ${ }^{3}$ \\ ( ( 1 Tropical Rainforest Ecosystem Research Station, Xishuangbanna Tropical Botanical Garden, the Chinese Academy of \\ Sciences, Mengla, Yunnan 666303, China) \\ (2 Institute of Ecology and Geobotany, Yunnan University, Kunming 650091, China) \\ ( 3 Mengla Nature Reserve Service, Xishuangbanna Bureau of National Nature Reserve, Mengla, Yunnan 666300, China)
}

\begin{abstract}
Vast areas of secondary tropical forest occur in Xishuangbanna owing to slash and burn cultivation and the destruction of tropical forest, which is a huge carbon and nutrient element bank. In order to know the dynamics of growth and bio-productivity of secondary tropical forests in different stages, "size class standard tree" and "the dimension analysis" methods were used to estimate the net primary productivity of four secondary tropical forests in different stand ages in Xishuangbanna. The results showed that the net primary productivity of four stands increases with stand age, which was $1154.3 \mathrm{~g} \cdot \mathrm{m}^{-2} \cdot \mathrm{a}^{-1}$ in 5 -year-stand, 1348.5 $\mathrm{g} \cdot \mathrm{m}^{-2} \cdot \mathrm{a}^{-1}$ in 10-year-stand, $2212.1 \mathrm{~g} \cdot \mathrm{m}^{-2} \cdot \mathrm{a}^{-1}$ in 14 -year-stand, and $2660.1 \mathrm{~g} \cdot \mathrm{m}^{-2} \cdot \mathrm{a}^{-1}$ in 22 -yearstand respectively. The allocation of net primary productivity in four stands showed that annual net growth had the highest net productivity, which was $93.82 \%, 92.83 \%, 91.72 \%$ and $92.09 \%$ in four stands respectively, leaf grazed ranked the second and represented $4.97 \%, 3.92 \%, 5.23 \%$ and $3.96 \%$ respectively, and reproductive parts contributed $1.20 \%, 3.25 \%, 3.05 \%$ and $3.95 \%$ respectively.

In the allocation of net primary productivity among different parts of plants in four stands, the net primary productivity of stem ranked the first, which occupied $35.79 \%$ of the total in 5-year-stand, $38.96 \%$ in 10 year-stand, $38.82 \%$ in 14-year-stand and $35.94 \%$ in 22-year-stand, and that of root was the second which made $23.03 \%, 21.38 \%$ and $23.18 \%$ of the total in 5-year-stand, 10-year-stand and 14-year-stand respectively except that of $19.26 \%$ of the total in 22 -year-stand. Branch productivity increased with the stand age from $15.54 \%$ of the total in 5-year-stand to $23 \%$ of the total in 22-year-stand, while leaf contributed $23.53 \%, 17.81 \%, 18.50 \%$ and $18.49 \%$ of the total in four stands respectively which gradually decreased with the stand age. Although reproductive parts contributed only a little, it also increased from $1.20 \%$ of the
\end{abstract}


total in 5-year-stand to $3.95 \%$ of the total in 22-year-stand.

Concerning the allocation of net primary productivity in different layers of four stands, the net primary productivity of the tree layer increased with the stand age which was $69.07 \%, 74.52 \%, 66.07 \%$ and $93.74 \%$ of the total in four stands respectively, and net primary productivity of shrub layer did not increase until 14-year-stand, and then sharply dropped, which was $22.05 \%$ of the total in 5-year-stand, $19.49 \%$ in 10 -year-stand and $32.24 \%$ in 14-year-stand, but only $2.96 \%$ in 22-year-stand, while the net primary productivity of the herb layer decreased from $8.01 \%$ in 5-year-stand to $4.41 \%$ in 10 -year-stand, and that of liana plants increased with the stand age from $0.87 \%$ in 5 -year-stand to $3.30 \%$ in 22 -year-stand.

The index of leaf area $(L A I)$ in four stands increased with the stand age from 2.70 in 5-year-stand to 7.41 in 22-year-stand, which was lower than that of other forests. The optimum regression models of the organic growth of the dominant plants and the sample trees in arborous layer for four stands were built. These models can be used to estimate net primary productivity of the same secondary tropical forests in Xishuangbanna.

Compared with other tropical forests, net primary productivity of 22-year-stand was higher than that of tropical seasonal rainforest $\left(2576.4 \mathrm{~g} \cdot \mathrm{m}^{-2} \cdot \mathrm{a}^{-1}\right)$ in Xishuangbanna, and net primary productivity of aboveground parts in 22-year-stand was also higher than that of a 20 -year-stand of secondary tropical forest in Northeastern India.

From the results, we can conclude that secondary tropical forest which regenerated from tropical rain forest after slash and burn cultivation in Xishuangbanna can grow fast under protection. So taking protective measures for vast secondary tropical forest is an effective way to speed recovery.

Key words Net primary production, Secondary tropical forest, Xishuangbanna

植物群落的生物量和生产力是研究森林物质生 产和群落养分动态的基础。作为地球上生物多样性 最丰富、生物群落结构最复杂、对全球气候有着重要 影响的热带雨林所受到的破坏和面积的急剧减少， 已成为国际社会倍受关注的焦点。目前世界上热带 森林破坏后所形成的次生林面积已超过 60 亿公顷 （Brown \& Lugo, 1990), 在西双版纳地区, 次生灌丛 的面积就占西双版纳国土面积的 $26.04 \%$ (刘隆等, 1990）。大面积的热带次生林是一个巨大的 C 库和 养分库, 它的存在与发展在全球 $\mathrm{C}$ 循环中起着十分 重要的作用（Kauffman et al., 1995；1998）。同时全 球 $\mathrm{C}$ 模型的设计与 $\mathrm{C}$ 败量的估算需要森林净初级 生产力的野外测定数据, 对世界范围内各类森林群 落净初级生产力的测算和掌握则成为当前一项非常 紧迫的重要研究内容 (Clark et al., 2001)。在热带 森林大面积锐减的今天, 掌握和了解热带次生林在 不同生长发育阶段的生物量和净初级生产力的动态 变化规律, 为全球森林 $\mathrm{C}$ 贮量的估算提供可靠的基 本数据, 以及对热带森林的保护、恢复和发展, 热带 退化生态系统的修复与重建都具有重要意义。

森林群落生物量和生产力的研究, 始于 100 多 年前德国科学家对几种森林的树枝落叶量和木材重 量的测定 (Ebermeryer，1876）。对全球范围内的各种 生态系统类型生物量与生产力的研究工作则随着以 研究各种生态系统生物量和生产力为中心的国际生 物学计划 (IBP) 的实施而开展起来。众多学者对全 球各生物区域的森林群落的生物量和生产力的估算
进行了较全面的比较分析, 获得了主要森林生态系 统类型和主要气候带的生物量和生产力 (Reichle et al., 1975; Lieth \& Whittaker, 1975; Lieth, 1978; Cannell, 1982)。我国对森林群落生物量和生产力的 研究工作则始于 20 世纪 70 年代末期, 国内众多学 者先后开展了从温带针叶林、亚热带常绿阔叶林到 热带雨林的研究 (李文华等, 1981; 冯宗炜等, 1982; 陈灵芝等, 1986; 邱学忠等, 1984; 陈章和等, 1993; 党 承林等, 1992; 黄全等, 1991; 李意德等, 1992; 冯志立 等, 1998; 郑征等, 1999a；1999b), 其中尤以人工林生 物量与生产力的研究报道较多 (冯宗炜等, 1982; 周 世强等, 1991; 高智慧等, 1992; 彭少麟等, 1992; 罗天 祥等, 1997)。但这些研究均局限于人工林和天然 林, 各类次生林的生物量和生产力则研究较少。热 带次生林的生物量则在 20 世纪 90 年代才开始对海 南岛和西双版纳的热带次生林的生物量进行了初步 研究 (李意德等, 1992; 唐建维等, 1998; 冯志立等, 1999; 施济普等, 2001), 但对热带次生林生产力的 研究则还未见报道。

唐建维等(1998)已对西双版纳不同林龄的热带 次生林生物量的动态变化趋势作了初步报道, 但它 仅反映了单位面积上的现存量即植物干物质的积累 量。而初级生产量是生产者通过光合作用在单位时 间内单位面积上所生产的有机物质, 它比生物量更 能揭示出生态系统中物质和能量的生产、积累、分配 及转移规律, 是生态系统群落功能的反映。为了更 好地了解和掌握热带次生林在恢复过程中的物质生 
产规律, 本文则测定了 4 块不同林龄的热带次生林 的净初级生产量, 试图在以下 3 个方面作一些探讨: 1) 热带次生林的净初级生产量随着林龄的增长的动 态变化;2)随着林龄的增长净初级生产量的层次分 配; 3 ) 随着林龄的增长净初级生产量的器官分配。

1 样地的自然环境与群落结构特征

4 块不同林龄的热带次生林样地的自然环境、 样地概况和群落结构特征以及每块样地样木数量的 选取和收获方法已另文详细描述(唐建维等, 1998)。

\section{2 研究方法}

\section{1 乔木各器官生长量的测定}

树干生长量: 在样木伐倒后, 清数树干基部的年 轮, 将该株树干的生物量除以年轮数即得该样木的 年平均生长量。

枝生长量: 将每一树枝从树干上锯下后, 并区分 当年生枝 (新枝) 和老枝, 分别清数其树枝基部的年 轮, 并测定枝的长度, 将该枝的生物量除以该枝的年 轮数, 即得老枝的平均生长量。枝的生长量即为老 枝的平均生长量与当年生枝 (新枝) 的生长量之和。

根生长量: 将根系从地下尽量全部挖出, 分为根 颈、主根、侧根和细根 $(\leqslant 2 \mathrm{~mm})$, 根颈具有和树干同 样的年龄; 将主根与根颈锯断后, 清数主根基部的年 轮; 侧根的年轮较难清数, 将其视为与主根具有同样 的年轮数; 各部分的生物量除以其年龄即得到其生 长量。细根的生物量即为其生长量。

叶生长量: 将乔木区分为常绿和落叶种类, 落叶 树种的叶的生物量即为生长量; 常绿种类则很难区 分老叶的年龄, 将当年生叶与老叶分检出来, 其当年 生叶的生物量即为叶的年生长量。常绿种类当年生 叶和老叶的区别可根据: 1 ) 当年生枝, 因当年生枝的 颜色与老枝不一样;2)叶的颜色, 当年生叶的颜色与 老叶不一样。

\section{2 乔木层生长量}

根据乔木层样木各器官的生长量所建立的优化 回归模型推算出乔木层的生长量。乔木层的净初级 生产量是树干、枝、叶、花果、根等器官的净生长量总 和。

\section{3 灌木层生长量}

清数每株个体茎的基部的年轮数, 将其干重除 以该株的年轮数, 即得该株的年生长量。根区分为 主根和细根后, 主根的年龄则与该株个体的年龄一 致。细根的生物量则是年生长量。灌木层的生产量
即为各灌木种类的生物量被其年龄所除而得, 10 个 $2 \mathrm{~m} \times 2 \mathrm{~m}$ 小样方内各种类的生长量之和换算成每 年单位面积 $\left(\mathrm{m}^{2}\right)$ 上的干重即为灌木层的生长量。

\section{4 草本层生长量}

因只有 5 年生、 10 年生林分内的小样方内采集 到了一年生的马唐( Digitaria ciliaris), 故其全部重量 为生产量。将 10 个 $2 \mathrm{~m} \times 2 \mathrm{~m}$ 小样方的净生长量换 算成每年单位面积 $\left(\mathrm{m}^{2}\right)$ 上的干重即为草本层的净生 长量。

\section{5 层间植物生长量}

层间植物的枝、叶、根的生长量与乔木层枝、叶、 根的生产量计算方法一样。将每样地内 10 个 $2 \mathrm{~m} \times$ $2 \mathrm{~m}$ 上的层间植物的净生长量换算成每年单位面积 $\left(\mathrm{m}^{2}\right)$ 上的干重, 即为层间植物的净生长量。

\section{6 花果的生产量}

在每块样地中随机架设 10 个 $0.2 \mathrm{~m}^{2}$ 的收集 器, 每个月收集 1 次, 从调落的叶、枝和杂屑中分检 出花果, 在 $75{ }^{\circ} \mathrm{C}$ 下烘干至恒重, 计算出各林分的花 果年调落物量。

\section{7 叶面积指数的测定}

采用叶面积比重法测定 (王义弘等, 1990)。

\section{3 结果与分析}

\section{1 乔木层器官的净生长量及其分配}

\subsection{1 乔木层器官年生长量的优化回归模型}

根据乔木层每株样木各器官的生长量, 采用多 种常见的线性和非线性回归模型对各群落中的优势 种及所有的样木加以拟合, 从中选取相关系数最高 者作为优化回归模型。乔木层各器官年生长量的优 化回归模型见表 1 , 所有的模型均达到了极显著水 平, 除个别器官的相关系数稍低一点外, 相关系数都 很高。

\section{1 .2 乔木层器官的净生长量及其分配}

用表 1 中的优化回归模型分别推算出各样地所 有立木的器官生长量, 将其生长量之和折算成 $\mathrm{g} \cdot \mathrm{m}^{-2} \cdot \mathrm{a}^{-1}$ 即为乔木层的生长量 (表 2 )。从表 2 可 见, 乔木层器官的净生长量以 22 年生林分最高, 分 别是 14 年生、 10 年生、 5 年生林分的 1.58 倍、 2.34 倍和 3.13 倍, 这表明热带次生林乔木层的净生长量 随林龄而迅速增长。就乔木层各器官的净生长量分 配比例的大小而言, 4 个林分都为: 茎 > 枝 > 根 > 叶, 显而易见, 在不同年龄的林分中, 乔木层净生长 量在各器官中的分配比例均以茎的比例为最大, 其 次为枝, 叶最小。 
表 1 林分主要优势种及乔木层器官生长量的优化回归模型

Table 1 The optimum regression models of different dominant plants and organic growth in the sample trees of arborous layer in four stands of tropical secondary forest

\begin{tabular}{|c|c|c|c|c|}
\hline $\begin{array}{c}\text { 名称 }(\text { 林龄 }) \\
\text { Name }(\text { Stand age })\end{array}$ & $\begin{array}{l}\text { 器官 } \\
\text { Organ }\end{array}$ & $\begin{array}{l}\text { 株数 } \\
\text { Samples }\end{array}$ & $\begin{array}{c}\text { 优化回归模型 } \\
\text { Optimun regression models }\end{array}$ & $\begin{array}{c}\text { 相关系数 } \\
\text { Regression } \\
\text { coefficient }(R)\end{array}$ \\
\hline $\begin{array}{l}\text { 中平树 } \\
\text { Macaranga denticulata }\end{array}$ & $\begin{array}{l}\text { 茎 Stem } \\
\text { 枝 Branch } \\
\text { 叶 Leaf } \\
\text { 根 Root }\end{array}$ & 13 & $\begin{array}{l}P s=1.288028 E-02\left(D^{2} H\right)^{0.7744308} \\
P b=0.164406+2.971995 E-03\left(D^{2} H\right) \quad(D \geqslant 4.0 \mathrm{~cm} \\
\left.P l=0.1910447+2.255185 E-03\left(D^{2} H\right) \quad H \geqslant 4.0 \mathrm{~m}\right) \\
P r=4.057344 E-03\left(D^{2} H\right)^{0.8412598}\end{array}$ & $\begin{array}{l}0.9496^{*} \\
0.9802^{*} \\
0.9863^{*} \\
0.9689^{*}\end{array}$ \\
\hline $\begin{array}{l}\text { 白背桐 } \\
\text { Mallotus paniculatus }\end{array}$ & $\begin{array}{l}\text { 茎 Stem } \\
\text { 枝 Branch } \\
\text { 叶 Leaf } \\
\text { 根 Root }\end{array}$ & 10 & 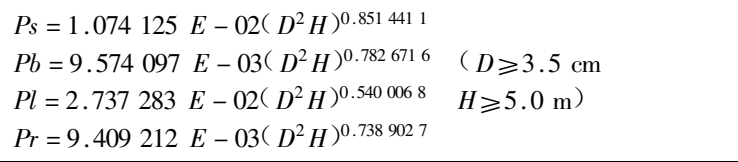 & $\begin{array}{l}0.9862^{*} \\
0.9293 * \\
0.9232^{*} \\
0.9498^{*}\end{array}$ \\
\hline $\begin{array}{l}\text { 鸡血藤 } \\
\text { Millettia leptobotrya }\end{array}$ & $\begin{array}{l}\text { 茎 Stem } \\
\text { 枝 Branch } \\
\text { 叶 Leaf } \\
\text { 根 Root }\end{array}$ & 13 & 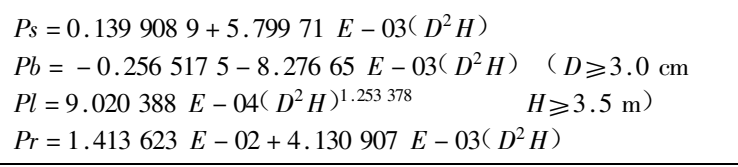 & $\begin{array}{l}0.9331^{*} \\
0.9772^{*} \\
0.9728^{*} \\
0.9835^{*}\end{array}$ \\
\hline $\begin{array}{l}\text { 蒲桃 } \\
\text { Syzygium brachyan- } \\
\text { therum }\end{array}$ & $\begin{array}{l}\text { 茎 Stem } \\
\text { 枝 Branch } \\
\text { 叶 Leaf } \\
\text { 根 Root }\end{array}$ & 12 & $\begin{array}{l}P s=1.370677 E-02\left(D^{2} H\right)^{0.8305878} \\
P b=0.2384497+2.525498 E-03\left(D^{2} H\right) \quad(D \geqslant 2.5 \mathrm{~cm} \\
\left.P l=5.978666 E-03\left(D^{2} H\right)^{0.8049731} \quad H \geqslant 4.5 \mathrm{~m}\right) \\
P r=2.2001006 E-02\left(D^{2} H\right)^{0.8834438}\end{array}$ & $\begin{array}{l}0.9765^{*} \\
0.9964^{*} \\
0.9792^{*} \\
0.9802^{*}\end{array}$ \\
\hline $\begin{array}{l}5 \text { 年生林分 } \\
5 \text {-year-stand }\end{array}$ & $\begin{array}{l}\text { 茎 Stem } \\
\text { 枝 Branch } \\
\text { 叶 Leaf } \\
\text { 根 Root }\end{array}$ & 28 & $\begin{array}{l}P s=1.766624 E-02\left(D^{2} H\right)^{0.701040} \\
P b=3.156950 E-02+3.43847 E-03\left(D^{2} H\right) \quad(D \geqslant 3.5 \mathrm{~cm} \\
\left.P l=1.731265 E-03\left(D^{2} H\right)^{1.068068} \quad H \geqslant 4.0 \mathrm{~m}\right) \\
P r=5.682328 E-03\left(D^{2} H\right)^{0.8248223}\end{array}$ & $\begin{array}{l}0.9496^{*} \\
0.9577^{*} \\
0.9655^{*} \\
0.9033^{*}\end{array}$ \\
\hline $\begin{array}{l}10 \text { 年生林分 } \\
10 \text {-year-stand }\end{array}$ & $\begin{array}{l}\text { 茎 Stem } \\
\text { 枝 Branch } \\
\text { 叶 Leaf } \\
\text { 根 Root }\end{array}$ & 41 & 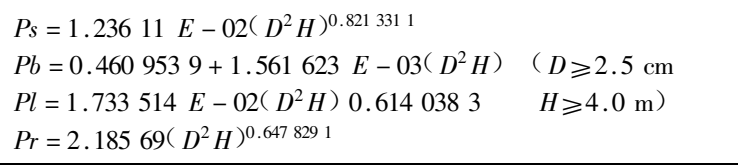 & $\begin{array}{l}0.9821^{*} \\
0.9598^{*} \\
0.9482^{*} \\
0.9447^{*}\end{array}$ \\
\hline $\begin{array}{l}14 \text { 年生林分 } \\
14 \text {-year-stand }\end{array}$ & $\begin{array}{l}\text { 茎 Stem } \\
\text { 枝 Branch } \\
\text { 叶 Leaf } \\
\text { 根 Root }\end{array}$ & 43 & 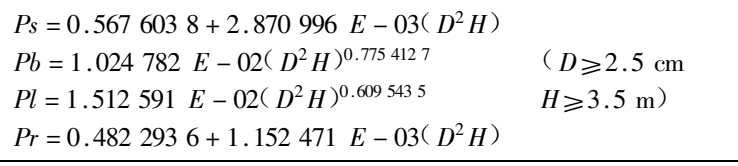 & $\begin{array}{l}0.9813^{*} \\
0.9271^{*} \\
0.9416^{*} \\
0.9378^{*}\end{array}$ \\
\hline $\begin{array}{l}22 \text { 年生林分 } \\
22 \text {-year-stand }\end{array}$ & $\begin{array}{l}\text { 茎 Stem } \\
\text { 枝 Branch } \\
\text { 叶 Leaf } \\
\text { 根 Root }\end{array}$ & 40 & $\begin{array}{ll}P s=1.259098 E-02\left(D^{2} H\right)^{0.7535645} & \\
P b=8.87132 E-03\left(D^{2} H\right)^{0.7157333} & (D \geqslant 2.5 \mathrm{~cm} \\
P l=0.1627494+5.865543 E-04\left(D^{2} H\right) & H \geqslant 3.0 \mathrm{~m}) \\
P r=5.757267 E-02\left(D^{2} H\right)^{0.7455342} & \end{array}$ & $\begin{array}{l}0.9131^{*} \\
0.9446^{*} \\
0.9607^{*} \\
0.9786^{*}\end{array}$ \\
\hline
\end{tabular}

$*: p<0.001$

乔木层净生长量在器官中的分配比例随林龄的 变化呈现出一定规律: 茎随林龄而逐渐递减; 枝随林 龄而逐渐递增; 叶从 5 年生林分到 10 年生林分稍有 下降之后又随林龄缓慢地增长, 但仅占 $1 / 7$ 左右。 根的分配比例则随林龄而缓慢地上升, 5 年生林分 约占 $1 / 6$, 其余 3 种林分则占 $1 / 5$ 以上。

\section{2 灌木层器官的净生长量及其分配}

4 个林分灌木层器官的净生长量 (表 2) 以 14 年 生林分为最高,约是 5 年生林分的 2.66 倍、10 年生 林分的 $2.60,22$ 年生林分的 9.14 倍。各器官净生 长量的分配比例顺序为: 5 年生林分的根 $>$ 叶 $>$ 茎 $>$ 枝, 10 年生、 14 年生林分的茎 > 根 > 叶 > 枝, 22 年 生林分则为茎 $>$ 叶 $>$ 根 $>$ 枝, 说明灌木层器官的净 生长量的分配比例在开始时以根所占的比例最大,
叶次之, 枝最小; 随着时间的推移, 以茎所占的比例 为最大, 其物质的生产与积累转移到以茎为主。

灌木层的净生长量在器官中的分配比例随林龄 变化的规律是: 茎随林龄增长到 10 年生林分后又逐 渐下降; 而枝则随林龄呈波浪式递增; 叶在开始时下 降后又随林龄逐渐上升; 根随林龄而逐渐减小。

\section{3 草本层及层间植物器官的净生长量及其分配}

草本植物的器官净生长量 (表 2)5 年生林分为 $92.5 \mathrm{~g}^{\bullet} \mathrm{m}^{-2} \cdot \mathrm{a}^{-1}$, 其器官分布以叶所占的比例最大, 约占 $1 / 2$; 茎不足 $1 / 3$, 根占 $1 / 5$ 以上。 10 年生林分 为 $59.5 \mathrm{~g} \cdot \mathrm{m}^{-2} \cdot \mathrm{a}^{-1}$, 其器官分配的比例与 5 年生林 分基本一致。

层间植物的净生长量 (表 2) 随林龄而逐渐上 升, 22 年生林分的净生长量约是 5 年生林分的 8.8 
倍, 10 年生林分的 4.4 倍, 14 年生林分的 2.4 倍。 其器官分配以茎所占的比例最大, 约占 $1 / 2 \sim 2 / 3$; 根次之; 枝最少, 约占 $1 / 20 \sim 1 / 10$ 。

\section{4 林分的净生长量及其分配}

4 个不同林龄的次生林林分的净生长量(表 2) 随林龄而增长, 22 年生林分分别是 14 年生林分的 1.21 倍, 10 年生林分的 1.97 倍, 5 年生林分的 2.26 倍。林分的净生长量尤以 10 年生林分到 14 年生林 分的增长幅度最大, 此后其增长速率又缓慢下来。 14 年生林分的净生长量比 10 年生林分高 786.65 $\mathrm{g} \cdot \mathrm{m}^{-2} \cdot \mathrm{a}^{-1}$, 而 10 年生林分比 5 年生林分仅高 $179.08 \mathrm{~g} \cdot \mathrm{m}^{-2} \cdot \mathrm{a}^{-1}, 22$ 年生林分比 14 年生林分高出 $420.83 \mathrm{~g} \cdot \mathrm{m}^{-2} \cdot \mathrm{a}^{-1}$ 。

3.4 .1 林分净生长量的层次分配

林分净生长量的层次分布 (表 2) 均以乔木层的 分配比例最大, 尤以 22 年生林分最突出, 占整个林 分净生长量的 $93.51 \%, 10$ 年生林分次之, 14 年生林 分最小; 灌木层以 14 年生林分为最大, 5 年生林分 次之, 22 年生林分为最小。这表明灌木层的净生长 量的增长在 14 年生林分达到高峰后随着林分郁闭 度的增大, 其增长速率又急剧下降。草本植物的净 生长量随林龄而递减, 而层间植物则随林龄而逐渐 增长。

3.4 .2 林分净生长量的器官分配
林分净生长量的器官分配随林龄而有所不同 (表 2 ), 但都以茎所占的比例最大, 约占 $2 / 5$, 且随林 龄增长到 14 年生林分后又下降; 枝所占的比例则随 林龄呈波浪式增长, 5 年生林分和 14 年生林分约占 $1 / 6,10$ 年生林分约占 $1 / 5,22$ 年生林分约为 $1 / 4$; 叶 所占的比例随林龄逐渐下降到 14 年生林分后又有 所增长, 5 年生林分约占 $1 / 5$, 其余 3 个林分约占 $1 / 7$; 根所占的比例随林龄呈波浪式地下降, 5 年生 和 14 年生林分占 $1 / 4$ 以上, 10 年生林分不足 $1 / 4,22$ 年生林分约占 $1 / 5$; 各林分器官分配的比例大小顺 序是: 5 年生林分的: 茎 > 根 > 叶 > 枝, 10 年生和 14 年生林分的: 茎 > 根 > 枝 > 叶, 22 年生林分的: 茎 > 枝 $>$ 根 $>$ 叶, 说明热带次生林在演替的初期阶段主 要是以茎的生长为主, 根系的生长也较旺盛, 而枝的 生长则随林龄逐渐加快。

\section{5 林分的净初级生产总量及其分配}

在实际工作中,由于地下部分的枯死量难以测 定, 故本文的净初级生产总量只包括林分的净生长 量、花果量和叶被采食量(表 3)。各林分叶的被采 食量见唐建维等(1998) 文献。从表 3 可知, 各林分 的净生长量占总净初级生产量的 $90 \%$ 以上, 调落物 量和叶被采食量则非常少, 两者合计所占的比例不 到 1/10。从净初级生产总量来看: 林分的净初级生 产量随林龄迅速增长, 22年生林分的净初级生产量

表 24 个林分各层次净生长量的器官分布

Table 2 The allocation of net growth among different parts of plants in different layers of four stands

\begin{tabular}{|c|c|c|c|c|c|c|c|c|c|c|c|}
\hline \multirow{2}{*}{$\begin{array}{l}\text { 层次 } \\
\text { Layer }\end{array}$} & \multirow{2}{*}{$\begin{array}{c}\text { 林龄 } \\
\text { Stand age (a) }\end{array}$} & \multicolumn{2}{|c|}{ 茎 Stem } & \multicolumn{2}{|c|}{ 枝 Branch } & \multicolumn{2}{|c|}{ 叶 Leaf } & \multicolumn{2}{|c|}{ 根 Root } & \multicolumn{2}{|c|}{ 总计 Total } \\
\hline & & $\begin{array}{c}\text { 净生长量 } \\
\text { NG }\end{array}$ & $\%$ & $\begin{array}{c}\text { 净生长量 } \\
\text { NG }\end{array}$ & $\%$ & $\begin{array}{c}\text { 净生长量 } \\
\mathrm{NG}\end{array}$ & $\%$ & $\begin{array}{c}\text { 净生长量 } \\
\text { NG }\end{array}$ & $\%$ & $\begin{array}{c}\text { 净生长量 } \\
\text { NG }\end{array}$ & $\%$ \\
\hline & 5 & 327.0 & 44.7 & 166.6 & 22.8 & 112.4 & 15.4 & 125.4 & 17.14 & 731.4 & 100 \\
\hline 乔木层 & 10 & 379.3 & 40.9 & 223.6 & 25.3 & 122.8 & 13.3 & 190.8 & 20.6 & 916.5 & 100 \\
\hline Tree & 14 & 563.0 & 42.3 & 310.7 & 23.3 & 180.5 & 13.6 & 276.4 & 20.8 & 1330.6 & 100 \\
\hline & 22 & 887.4 & 38.7 & 583.6 & 25.5 & 343.0 & 14.9 & 476.7 & 20.8 & 2290.7 & 100 \\
\hline & 5 & 53.9 & 21.6 & 12.2 & 4.9 & 55.1 & 22.1 & 127.8 & 51.3 & 249.0 & 100 \\
\hline 灌木层 & 10 & 113.9 & 44.5 & 25.2 & 9.8 & 34.8 & 13.6 & 82.2 & 32.1 & 256.1 & 100 \\
\hline Shrub & 14 & 271.8 & 41.0 & 49.9 & 7.5 & 111.3 & 16.8 & 229.9 & 34.7 & 662.9 & 100 \\
\hline & 22 & 27.9 & 38.4 & 6.3 & 8.7 & 24.3 & 33.5 & 14.0 & 19.3 & 72.5 & 100 \\
\hline 草本层 & 5 & 27.5 & 29.8 & & & 44.3 & 47.90 & 20.7 & 22.4 & 92.5 & 100 \\
\hline Herb & 10 & 17.7 & 29.7 & & & 28.6 & 48.2 & 13.2 & 22.2 & 59.5 & 100 \\
\hline & 5 & 4.6 & 46.9 & 0.5 & 5.5 & 2.2 & 22.5 & 2.5 & 25.1 & 9.8 & 100 \\
\hline 层间植物 & 10 & 13.9 & 70.6 & 1.9 & 9.8 & 1.8 & 8.8 & 2.2 & 10.8 & 19.8 & 100 \\
\hline Liana & 14 & 24.0 & 67.8 & 3.2 & 9.0 & 1.6 & 4.5 & 6.6 & 18.7 & 35.4 & 100 \\
\hline & 22 & 40.5 & 46.9 & 4.8 & 5.5 & 19.5 & 22.5 & 21.7 & 25.1 & 86.5 & 100 \\
\hline & 5 & 413.1 & 38.1 & 179.4 & 16.6 & 214.2 & 19.8 & 276.3 & 25.5 & 1083.0 & 100 \\
\hline 总计 & 10 & 525.4 & 42.0 & 250.8 & 20.0 & 187.3 & 14.9 & 288.3 & 23.0 & 1251.8 & 100 \\
\hline Total & 14 & 858.8 & 42.3 & 363.8 & 17.9 & 293.5 & 14.5 & 512.9 & 25.3 & 2028.9 & 100 \\
\hline & 22 & 955.8 & 39.0 & 594.7 & 24.3 & 386.8 & 15.8 & 512.4 & 20.9 & 2449.6 & 100 \\
\hline
\end{tabular}


表 34 个林分的净初级生产量

Table 3 The total net primary productivity in four stands

\begin{tabular}{|c|c|c|c|c|c|c|c|c|}
\hline \multirow{2}{*}{$\begin{array}{c}\text { 林龄 } \\
\text { Stand age (a) }\end{array}$} & \multicolumn{2}{|c|}{$\begin{array}{l}\text { 净生长量 } \\
\text { Net growth }\end{array}$} & \multicolumn{2}{|c|}{$\begin{array}{c}\text { 花果量 } \\
\text { Reproductive parts }\end{array}$} & \multicolumn{2}{|c|}{$\begin{array}{c}\text { 叶被采食量 } \\
\text { Leaf grazed }\end{array}$} & \multicolumn{2}{|c|}{$\begin{array}{l}\text { 总计 } \\
\text { Total }\end{array}$} \\
\hline & $\mathrm{g} \cdot \mathrm{m}^{-2} \cdot \mathrm{a}^{-1}$ & $\%$ & $\mathrm{~g} \cdot \mathrm{m}^{-2} \cdot \mathrm{a}^{-1}$ & $\%$ & $\mathrm{~g} \cdot \mathrm{m}^{-2} \cdot \mathrm{a}^{-1}$ & $\%$ & $\mathrm{~g} \cdot \mathrm{m}^{-2} \cdot \mathrm{a}^{-1}$ & $\%$ \\
\hline 5 & 1083.0 & 93.82 & 13.9 & 1.20 & 57.4 & 4.97 & 1154.3 & 100 \\
\hline 10 & 1251.8 & 92.83 & 43.8 & 3.25 & 52.9 & 3.92 & 1348.5 & 100 \\
\hline 14 & 2028.9 & 91.72 & 67.5 & 3.05 & 115.7 & 5.23 & 2212.1 & 100 \\
\hline 22 & 2449.6 & 92.09 & 105.0 & 3.95 & 105.5 & 3.96 & 2660.1 & 100 \\
\hline
\end{tabular}

已达 $2660.1 \mathrm{~g} \cdot \mathrm{m}^{-2} \cdot \mathrm{a}^{-1}$, 约是 5 年生林分的 2.3 倍, 10 年生林分的 1.97 倍, 14 年生林分的 1.2 倍。这 表明西双版纳的热带雨林经刀耕火种撂荒后形成的 次生植被恢复较快, 具有较高的生物生产力。

4 个林分净初级生产量的器官分配 (表 4) 表明: 以茎所占的比例最大, 占 $1 / 3$ 以上; 其次为根, 占 $1 / 5$ 左右; 枝和叶为 $1 / 5 \sim 1 / 7$; 花果所占的比例相当低, 除 5 年生林分的花果特别少外, 其余约占 $1 / 33$ 左 右。林分净初级生产量的器官分配体现出一定的规 律性: 茎随林龄增长到 14 年生林分后下降; 枝、花果 随林龄而呈波浪式增长; 叶、根则随林龄呈逐渐下降 的趋势。

林分净初级生产量的层次分配(表 5) 以乔木层 所占的比例最大, 占 $2 / 3$ 以上, 特别是 22 年生林分, 占整个林分净初级生产量的 $93.74 \%$; 灌木层所占 的比例除 22 年生林分很少外, 其余 3 个林分约占
$1 / 5 \sim 1 / 3$; 草本层和层间植物所占的比例则相当少。 从各层次所占的比例可知: 乔木层所占的比例随林 龄呈波浪式增长; 灌木层随林龄呈波浪式增长到 14 年生林分后急剧下降; 草本层随林龄而递减; 层间植 物随林龄而上升。

\section{6 叶面积指数}

叶面积指数 $(L A I)$ 是反映植物群落生产力高低 的一个重要指标。对各林分采用叶面积比重法的测 定结果为: 5 年生林分为 $2.70,10$ 年生林分为 3.61 , 14 年生林分为 $7.21,22$ 年生林分为 7.41 , 由此可看 出各群落的叶面积指数随林龄而增大。从叶面积指 数与群落生产力的关系来看: 5 年生林分最小, 为 $2.70,22$ 年生林分最大, 为 7.41 , 其净生产量也是从 5 年生林分的最少的 $1154.3 \mathrm{~g} \cdot \mathrm{m}^{-2} \cdot \mathrm{a}^{-1}$ 增长到 22 年生林分最大的净生产量 $2660.1 \mathrm{~g} \cdot \mathrm{m}^{-2} \cdot \mathrm{a}^{-1}$ 。这 表明随着林分叶面积指数的增大, 其群落生产力也

表 44 个林分的净初级生产量的器官分配

Table 4 The allocation of net primary productivity among different parts of plants in four stands $\left(\mathrm{g}^{\bullet} \mathrm{m}^{-2} \cdot \mathrm{a}^{-1}\right)$

\begin{tabular}{|c|c|c|c|c|c|c|c|c|c|c|c|c|}
\hline \multirow{2}{*}{$\begin{array}{c}\text { 林龄 } \\
\text { Stand age (a) }\end{array}$} & \multicolumn{2}{|c|}{ 茎 Stem } & \multicolumn{2}{|c|}{ 枝 Branch } & \multicolumn{2}{|c|}{ 叶 Leaf } & \multicolumn{2}{|c|}{ 根 Root } & \multicolumn{2}{|c|}{$\begin{array}{c}\text { 花果 } \\
\text { Reproductive } \\
\text { parts }\end{array}$} & \multicolumn{2}{|c|}{ 总计 Total } \\
\hline & $\begin{array}{c}\text { 净生产量 } \\
\mathrm{NP}\end{array}$ & $\%$ & $\begin{array}{c}\text { 净生产量 } \\
\mathrm{NP}\end{array}$ & $\%$ & $\begin{array}{c}\text { 净生产量 } \\
\mathrm{NP}\end{array}$ & $\%$ & $\begin{array}{c}\text { 净生产量 } \\
\mathrm{NP}\end{array}$ & $\%$ & $\begin{array}{c}\text { 净生产量 } \\
\mathrm{NP}\end{array}$ & $\%$ & $\begin{array}{c}\text { 净生产量 } \\
\text { NP }\end{array}$ & $\%$ \\
\hline 5 & 413.2 & 35.79 & 179.4 & 15.54 & 271.6 & 23.53 & 276.3 & 23.93 & 13.9 & 1.20 & 1154.3 & 100 \\
\hline 10 & 525.4 & 38.96 & 250.8 & 18.60 & 240.2 & 17.81 & 288.3 & 21.38 & 43.8 & 3.25 & 1348.5 & 100 \\
\hline 14 & 858.8 & 38.82 & 363.8 & 16.44 & 409.2 & 18.50 & 512.9 & 23.18 & 67.5 & 3.05 & 2212.1 & 100 \\
\hline 22 & 955.8 & 35.94 & 594.7 & 22.36 & 491.8 & 18.49 & 512.4 & 19.26 & 105.0 & 3.95 & 2660.1 & 100 \\
\hline
\end{tabular}

NP: Net production $\left(\mathrm{g}^{\bullet} \mathrm{m}^{-2} \cdot \mathrm{a}^{-1}\right)$

表 54 个林分的净初级生产量的层次分配

Table 5 The allocation of net primary productivity in different layers of four stands

\begin{tabular}{|c|c|c|c|c|c|c|c|c|c|c|}
\hline \multirow{2}{*}{$\begin{array}{c}\text { 林齢 } \\
\text { Stand age (a) }\end{array}$} & \multicolumn{2}{|c|}{ 乔木层 Tree } & \multicolumn{2}{|c|}{ 灌木层 Shrub } & \multicolumn{2}{|c|}{ 草本层 Herb } & \multicolumn{2}{|c|}{ 层间植物 Liana } & \multicolumn{2}{|c|}{ 总计 Total } \\
\hline & $\begin{array}{c}\text { 净生产量 } \\
\text { NP }\end{array}$ & $\%$ & $\begin{array}{c}\text { 净生产量 } \\
\text { NP }\end{array}$ & $\%$ & $\begin{array}{c}\text { 净生产量 } \\
\mathrm{NP}\end{array}$ & $\%$ & $\begin{array}{c}\text { 净生产量 } \\
\mathrm{NP}\end{array}$ & $\%$ & $\begin{array}{c}\text { 净生产量 } \\
\text { NP }\end{array}$ & $\%$ \\
\hline 5 & 797.3 & 69.07 & 254.6 & 22.05 & 92.5 & 8.01 & 9.9 & 0.87 & 1154.3 & 100 \\
\hline 10 & 1004.9 & 74.52 & 262.8 & 19.49 & 59.5 & 4.41 & 21.3 & 1.58 & 1348.5 & 100 \\
\hline 14 & 1461.6 & 66.07 & 713.3 & 32.24 & & & 37.2 & 1.68 & 2212.1 & 100 \\
\hline 22 & 2493.5 & 93.74 & 78.8 & 2.96 & & & 87.8 & 3.30 & 2660.1 & 100 \\
\hline
\end{tabular}

NP: Net production $\left(\mathrm{g} \cdot \mathrm{m}^{-2} \cdot \mathrm{a}^{-1}\right)$ 
依次增大。与热带地区其它群落类型的叶面积指数 相比, 这 4 个林分的叶面积指数较低, 海南岛黎母山 山地雨林的 $L A I$ 为 9.572 , 尖峰岭热带山地雨林为 16.70 , 尖峰岭热带季雨林为 6.2 , 泰国的热带雨林达 12.3。这也许与林分的演替阶段有关, 因目前这 4 个林分正处于演替的初期阶段, 其群落的结构、林木 的径级结构及植物种类等均较为简单, 从目前这 4 个林分的 $L A I$ 值逐渐增加的趋势来看, 随着时间的 推移, 植物种类和群落结构的日趋丰富、复杂, 其 $L A I$ 将会增大。

\section{4 讨 论}

1)群落的生物量和生产力是群落结构、功能的 重要标志之一。4 块不同林龄的次生林的净初级生 产量的研究结果表明: 西双版纳的热带雨林经刀耕 火种撂荒后形成的次生林其净初级生产量的增长较 快。与本地区的原始热带季节雨林的净初级生产量 相比, 22 年生林分的净初级生产量 $\left(2660.1 \mathrm{~g} \cdot \mathrm{m}^{-2}\right.$. $\left.\mathrm{a}^{-1}\right)$ 已高于本地区的原始热带季节雨林的 $2576.4 \mathrm{~g}$ $\cdot \mathrm{m}^{-2} \cdot \mathrm{a}^{-1}$ (郑征等, 1999a；1999b)。虽然西双版纳 地处热带北缘, 热量和水分偏低, 处于热带雨林分布 的极限 (朱华, 1990), 22 年生林分地上部分的净初 级生产量 $\left(2147.7 \mathrm{~g} \cdot \mathrm{m}^{-2} \cdot \mathrm{a}^{-1}\right)$ 约是印度东北部同样 经刀耕火种撂荒后形成的 20 年生林分 $1800 \mathrm{~g} \cdot \mathrm{m}^{-2}$. $\mathrm{a}^{-1}$ (Toky \& Ramakrishnan, 1983) 的 1.2 倍。再从次生 林的生物量 (唐建维等, 1998)、群落的种类组成、结 构特征及其演替动态 (唐建维等, 1997; 1999)等方面 综合分析来看, 对已形成的次生林加以切实的保护, 是促使其尽快恢复成林的有效措施和途径之一。

2) 随着林龄的增长, 林分净初级生产量在层次 分配和器官分配上产生一定的波动, 灌木层和茎的 净初级生产量增长到 14 年生林分后下降, 这主要是 在 14 年生林分时, 占据群落乔木上层的先锋植物山 乌柏 (Sapium discolor)、白背桐 (Mallotus paniculatus) 的衰亡, 使原处于林木下层的小乔木、乔木幼树及灌 木树种得到了能充分生长发育的机会所致。这也正 是次生林在其发展过程中群落波动性的具体体现， 因为在演替的早期阶段, 先锋树种的死亡和更替及 其群落种类组成、结构特征的变化, 必然导致群落的 生物量和生产力随着群落的变化而发生波动( Peet, 1981)。

3)4 块不同林龄的次生林在一定程度上反映了 西双版纳热带次生林的净初级生产量随着林龄的增 长而呈现的动态变化趋势, 由于实际工作中的困难,
部分植物的器官并未完整地收集到, 如细根的挖掘、 攀缘至林冠上的藤本植物叶的收集等, 致使林分净 初级生产量的估算有所偏低。另一方面在同龄的样 地数量方面略显不足。在本项研究中, 针对植物在 其生长发育过程中各器官不同的发育进程, 分别清 数各器官的年龄来计算其生产量, 较准确、具体地反 映了各器官的生长量大小及林分的净初级生产总 量。

4)本文提出了西双版纳热带次生林在演替初期 阶段中林分的主要优势种及乔木层样木器官生长量 的优化回归模型, 可作为相似立地条件上热带次生 林净初级生产量估测的参考。

\section{参 考 文 献}

Brown, S. \& A. E . Lugo. 1990. Tropical secondary forests. Journal of Tropical Ecology, 6 (9) : $1 \sim 32$.

Cannell, M. G. R. 1982. World forest biomass and primary production data. London : Academic Press.

Chen, L. Z. (陈灵芝)，Q. L. Chen (陈清朗)，X. C. Bao (鲍显诚), J. K. Ren (任继凯), Y. G. Miao (缪有贵) \& Y. H. Hu (胡肄慧). 1986. Studies on Chinese arborvitae (Platycladus orientalis) forest and its biomass in Beijing. Acta Phytoecologica et Geobotanica Sinica (植物生态学与地植物学 学报), 10: 17 25. (in Chinese with English abstract)

Cheng, Z. H. (陈章和), H. D. Zhang (张宏达), B. S. Wang (主伯称) \& Z. Q. Zhang (张志权). 1993. Studies on biomass and its allocation of the evergreen broadleaved forest in Heishiding, Guangdong. Acta Phytoecologica et Geobotanica Sinica (植物生态学与地植物学学报), 17: 289 298. (in Chinese with English abstract)

Clark, D. A., S. Brown, D. W. Kicklighter, J. Q. Chambers, J. R. Thomlinson \& J. Ni. 2001. Measuring net primary production in forests: concepts and field methods. Ecological Applications, 11: $356 \sim 370$.

Dang, C. L. (党承林) \& Z. L. Wu (吴兆录). 1992. Studies on the net primary production for Castanopsis echidnocarpa community of monsoon evergreen broad-leaved forest. Journal of Yunnan University (云南大学学报), 14: $95 \sim 107$. (in Chinese with English abstract)

Ebermeryer, E. 1876. Die gesamte lehre der Waldstreu mit Rucksicht auf die chemische static des Waldbaues. Berlin: Julius Springer. 116.

Feng, Z.W. (冯宗炜), C. Y. Chen (陈楚芗), J. W. Zhang (张家武), K. P. Wang (王开平) \& J. L. Zhao (赵吉录). 1982. Biological productivity of two forest communities in Huitong county of Hunan province. Acta Phytoecologica et Geobotanica Sinica (植物生态学与地植物学丛刊), 6: $257 \sim 267$. (in Chinese with English abstract)

Feng, Z. L. (冯志立), Z. Zheng (郑征), J. H. Zhang (张建 侯)，M. Cao (曹敏)，L. Q. Sha (沙丽清) \& J. W. Deng (邓继武). 1998. Biomass and its allocation of a tropical wet seasonal rain forest in Xishuangbanna. Acta Phytoecologica Sinica (植物生态学报), 22: 481 488. (in Chinese with English abstract)

Feng, Z. L. (冯志立)，J. W. Tang (唐建维)，Z. Zheng (郑 征), Q. S. Song (宋启示), M. Cao (曹敏), J. H. Zhang (张建侯) \& J. W. Xie (解继武). 1999. Biomass dynamics of the pioneer Trema orientalis community in the early stages of secondary succession of tropical forest in Xishuangbanna. Chinese 
Journal of Ecology (生态学杂志), 18(5): 1 6. (in Chinese with English abstract)

Gao, Z. H. (高智慧)，G. H. Jiang (蒋国洪)，A.J. Xing (邢爱金) \& M. R. Yu (俞铭荣). 1992. A study on the biomass of Metasequoia glyptostroboides plantation in Zhebei plain. Acta Phytoecologica et Geobotanica Sinica (植物生态学 与地植物学学报), 16: 64 71. (in Chinese with English abstract)

Huang, Q. (黄全)，Y. D. Li (李意德)，J. Z. Lai (赖巨章) \& G. J. Peng (彭国金). 1991. Study on biomass of tropical mountain rain forest in Limushan, Hainan Island. Acta Phytoecologica et Geobotanica Sinica (植物生态学与地植物学学报), 15: 197 206. (in Chinese with English abstract)

Kauffman, J. B., D. L. Cummings, D. E. Ward \& R. Babbitt. 1995. Fire in the Brazilian Amazon: 1. Biomass, nutrient pools and losses in slashed primary forests. Oecologia, 104: $397 \sim 408$.

Kauffman, J. B., D. L. Cummings \& D. E. Ward. 1998. Fire in the Brazilian Amazon: 2. Biomass, nutrient pools and losses in cattle pasture. Oecologia, 113: $415 \sim 427$.

Li, W. H. (李文华), K. M. Deng (邓坤枚) \& F. Li (李飞). 1981. Study on biomass and primary production of main ecosystems in Changbai mountain. Research of Forest Ecosystem (森林 生态系统研究) , 2:34 50. (in Chinese with English abstract)

Li, Y. D. (李意德)，Q. B. Zeng (曾庆波)，Z.M. Wu (吴 仲民), Z. H. Du (杜志鹄), G. Y. Zhou (周光益), B. F. Chen (陈步峰), Z. C. Zhang (张振才) \& H. Q. Chen (陈 焕强). 1992. Study on biomass of tropical mountain rain forest in Jianfengling, Hainan province. Acta Phytoecologica et Geobotanica Sinica (植物生态学与地植物学学报), 16: 293 299. (in Chinese with English abstract)

Lieth, H. F. H. 1978. Patterns of primary production in the biosphere. Stroudsburg, Pennsylvania: Dowden, Hutchinson \& Ross, Inc.

Lieth, H. F. H. \& R. H. Whittaker. 1975. Primary productivity of biosphere. Berlin: Springer-Verlag.

Liu, L. (刘隆)，X.Z. Hu (胡相之)，Y. C. Yang (杨毓才), W. W. Liu (刘文蔚) \& R. X. Guo (郭瑞祥). 1990. Investigation on the land and economy in Xishuangbanna. Kunming: Yunnan People Press.

Luo, T. X. (罗天祥) \& S. D. Zhao (赵士洞). 1997. Patterns and mathematical models of Chinese-fir productivity in China. Acta Phytoecologica Sinica (植物生态学报), 21: 403 415 . (in Chinese with English abstract)

Peet, R. K. 1981. Changes in biomass and production during secondary forest succession. In: West, D. C., H. H. Shugart \& D. B. Botkin eds. Forest succession: concepts and application. New York: Springer-Verlag. $324 \sim 338$.

Peng, S. L. (彭少麟), Z. Y. Yu (余作岳)，W. Q. Zhang (张文其) \& X. P. Zeng (曾小平). 1992. Coenological analysis of five man-made forests on down-land in Heshan, Guangdong province. Acta Phytoecologica et Geobotanica Sinica (植物 生态学与地植物学学报), 16: 1 10. (in Chinese with English abstract)

Qiu, X. Z. (邱学忠), S. C. Xie (谢寿昌) \& G. F. Jing (荆
桂芬). 1984. A preliminary study on biomass of Lithocarpus xylocarpus forest in Xujiaba region, Ailao Mts., Yunnan. Acta Botanica Yunnanica (云南植物研究), 6: 85 92. (in Chinese with English abstract)

Reichle, D. E., J. F. Franklin \& D. E. Goodwell. 1975. Productivity of world ecosystems. Washington D. C.: National Academy of Sciences.

Shi, J. P. (施济普), J. W. Tang (唐建维), G. M. Zhang (张光明) \& K. J. Bai (白坤甲). 2001. A preliminary study on the biomass of plant community in swidden land after slash and burn in Xishuangbanna. Chinese Journal of Ecology (生态学杂 志), 20(5): 12 15. (in Chinese with English abstract)

Tang, J. W. (唐建维), J. H. Zhang (张建侯), Q. S. Song (宋启示) \& Z. L. Feng (冯志立). 1997. Analysis on the characteristic of Millettia laptobotrya community in Xishuangbanna. Guihaia (广西植物)，17: $338 \sim 344$. (in Chinese with English abstract)

Tang, J. W. (唐建维), J. H. Zhang (张建侯), Q. S. Song (宋启示), M. Cao (曹敏), Z. L. Feng (冯志立), C. L. Dang (党承林) \& Z. L. Wu (吴兆录). 1998. A preliminary study on the biomass of secondary tropical forest in Xishuangbanna. Acta Phytoecologica Sinica (植物生态学报), 22: 489 498. (in Chinese with English abstract)

Tang, J. W. (唐建维), J. H. Zhang (张建侯), Q. S. Song (宋启示) \& Z. L. Feng (冯志立). 1999. Community analysis on secondary tropical vegetation in Xishuangbanna. Chinese Journal of Applied Ecology (应用生态学报), 10: 135 139. (in Chinese with English abstract)

Toky, O. P. \& P. S. Ramakrishnan. 1983. Secondary succession following slash and burn agriculture in north-eastern India, I. Biomass, litterfall and productivity. Journal of Ecology, 71: 735 $\sim 745$.

Wang, Y. H. (王义弘), J. Q. Li(李俊清) \& Z. Q. Wang(王 政权). 1990. Methods of experiment and practice in forest ecology. Harbin: North-East Forestry University Press. 36. (in Chinese)

Zheng, Z. (郑征), H. M. Liu (刘宏茂), L. H. Liu (刘伦 辉), M. Cao (曹敏) \& Z. L. Feng (冯志立)。1999a。A study on biomass of the primary tropical seasonal rain forest in Xishuangbanna. Guihaia (广西植物), 19: 309 314. (in Chinese with English abstract)

Zheng, Z. (郑征), L. H. Liu (刘伦辉)，Z. L. Feng (冯志 立) , H. M. Liu (刘宏茂) \& M. Cao (曹敏). 1999b. The net primary production of the tropical seasonal rain forest in Xishuangbanna. Journal of Mountain Science (山地学报), 17: $212 \sim 217$. (in Chinese with English abstract)

Zhou, S. Q. (周世强) \& J. Y. Huang (黄金燕). 1991. A study on biomass and productivity of Larix mastersiana plantation in Sichuan. Acta Phytoecologica et Geobotanica Sinica (植物生 态学与地植物学学报), 15: 1 8. (in Chinese with English abstract)

Zhu, H. (朱华). 1990. Tropical rain forest vegetation in Xishuangbanna. Tropical Geography (热带地理), 10: 233 240. (in Chinese with English abstract) 